\title{
Stuttering Therapy - an integration of Speech Therapy and Psychotherapy.
}

\author{
M. ARON.
}

The utilization of psychotherapy and speech therapy together is fast being recognised as an indispensable approach in the majority of the up-to-date speech clinics. The integration of these two procedures is seen most clearly in therapy with stutterers, and combined they have very reasonably the same objective in view. There are probably few todary who still administer a purely mechanical and symptomatic approach to stuttering and on the other hand, few who ignore the symptom and are only concerned with psychotherapy. They are both necessary.

The stutterer presents himself originally at the clinic as an individual with feelings of fear and embarrassment and he possesses a symptom which is regarded as being abnormal by his society. He is not presenting an isolated overt symptom-there are a chain of symptoms, affected by one another and having profound influence upon the internal and external aspects of behaviour.

In the past it has been emphasized in many schools that speech therapy is dependent on other disciplines for its correct and stable maintenance, and that we must keep in mind the boundaries of our field. However, new techniques are continually being evolved where over-lapping into other fields cannot be avoided. Progress in the fields of work dealing with people appear to be slowly amalgamating and inter-relating. If we are going to look at a human being as a "gestalt" then perhaps we should look at the science dealing with him also as a "gestalt." That is not to say that we are eligible to practise in its entirety a science other than the one in which we are qualified; but we would be failing if we denied that we do use some necessary principles from other fields and that there is overlapping.

The very nature of a speech disorder demands an organismic therapy. Speech cannot be isolated from behorviour and personality. Goldstein (1) comes to the following conclusion as to the nature of language "Language is a means of the individual to come to terms with the outer world and to realize himself," and Eisenson (2) says "the function of speech is to cause response of thoughts, feelings or actions to occur in some- one". Language (speech) is a social institution and as such it cannot be removed from other aspects of our culture pertaining to ourselves and our thoughts without distortion to the picture as a whole. If we regard stuttering as avoidance behaviour $(3,5)$, and the stutterer as an individual on constant vigil so that he might avoid or postpone words and situations which are fearful to himselt, then we can expect an integrated approach of speech therapy and psychotherapy to be more fruitful. Psychotherapy deals with the individual making new adjustments to life and finding more satisfying relationships where he is temporarly unable to do so for himself. Sheehan (4) has said that stuttering not only expresses the nature of the stutterer's relationships but is in part determined by them. Deep psychotherapy is of no concern to the speech therapist, but nevertheless the basic principles used, including mental hygiene, become incorporated in speech therapy.

Group therapy for stutterers practised in parts of the States and Canada uses this combined approach. It deals with the handling of fear that the individual has generally and also the fears as regards his blocks, with the changes of attitudes towards himself, his speech and towards his particular societv group; as well as providing tools to enable him to appreciate the problem symptomatically and to change his pattern of stuttering. This approach is one practised by the "Iowa School" $(4,5,6,7)$, and is the one used by Douglas in Toronto which I observed.

Because of the use of this particular approach in these groups, i.e., the integration of psychotherapy and speech therapy, it can be expected that problems and changes in the individual will continually occur. The material is dynamic, personal and individual and the therapy can be described as $\alpha$ process in itself. Psychotherapy "is a procedure which is intended to make a progressive change in the patient" (8). Also because of the elements constituting and causing language and speech, defects and the rehabilitation of these defects must also cause changes in the individual and in his total expressions, 
If we regard a stutterer's progres's as being due only to speech therapy in its strictest definition, then we are incorrect, for the changes that occur and make progress possible are due, by definition, to the psychotherapeutic and speech therapeutic aspects of therapy. This was clearly illustrated to me when I observed stuttering group therapy. The groups emphasized the part that attitudes and personalities ploy. While using a mechanical approach to stuttering, a group on its own accord (because of the very nature of a group) would, I feel, still make demands for psychological concepts to be made explicit as regards their problems. Apart from the fact that group therapy is more expedient than individual therapy, it has many social and psychological facets. Some of these are:

(a) The group provides a ready "audiencereactor" and it can be considered as the first step in the stutterer's new social relationships.

(b) It provides for the stutterer a number of people who, having worked together with him, can understond his problem more readily than the outsider, can emphasize, support and counsel.

(c) The group can engage itself in feared activities and can enable the individual to do collectively what they otherwise might not have been able to do (9).

(d) Participation is made easier and more free than if an individual would have to attend meetings by himself. It is a more tolerable situation (10).

(e) Attitude and conflicts which previously the stutterer thought he alone was afflicted with, become rather common attitudes and conflicts that are exhibited by the group.

Three such groups were undertaken at the Speech Clinic at the Toronto Psychiatric Hospital while I was employed there during 1955. Douglas believes that the stutterer should be first educated in the problem of stuttering before dealing with the actual therapy. This should eliminate misunderstandings: clear up notions as to the cause. its nature and development; and indicate techniques and attitudes that will be used and sought after during the therapy process. The information helps to objectify his problem and will make clear to him the nature of his rehabilitation and make possible also for the intellectual appreciation of the problem.

These groups were handled with three different approaches as regards the educational period and was extended where possible into the therapeutic situation. (a) The directive-diadactic approach. Here the group was educated in the problem of stuttering as a group of speech students would be. This approach also carried over into most of the therapeutic sessions including personal problems. Points were moide and suggested but they were not pushed or stressed at all as regards the members acceptance or understanding of them. The least possible assistance was given in therapy unless it was made explicit by the members that they required assistance.

(b) The Socratic approach. This concept implies "that all knowledge lies within so that in reality education proper is a process of recollection or recognition. The truth so acquired is reached by a personal discovery." The word "educate" implying the same, derived from the Latin, "educ", meaning "to lead out," "to draw forth," "to elicit." This approach was therefore non-directive, bearing similar principles to that used in "non-directive counselling." Information was drawn out by asking the right questions at the right time. The members of the group disdiscussed problems in the order that they

\section{Vacancy for Speech Therapist}

\section{THE EASTERN PROVINCE CEREBRAL PAISY SCHOOL, PORT ELIZABETH}

One Speech Therapist is required from the beginning of the first term 1957.

Applications should be addressed to

Mrs. H. LURIE,

30. Wares Road,

Port Elizabeth. 
desired and any point that was made in the group was made by the group itself. At times the clinician recapitulated in his own words what was being said. Where possible this was carried over into theropy, but at times because of circumstances dealing with individual problems, it could not always be as non-directive as desired. The main responsibility was placed on the patient's shoulders and "support" was implied. He was encouraged to carry this responsibility rather than to lean on the clinician.

(c) The directive-explanatory approach. Here the group was educated in the problem of stuttering most directively. They were taught as a group of children would be. Each step was most carefully explained over and over again, simplified and illustrated. Therapy was dealt with in the same monner and "laid on the line." (i.e., everything was handed to them on a platter).

The three groups consisted of carefully selected stutterers. With the aid of tests, they were selected with regard to being intelligent and for being relatively free from the possibility of emotional breakdown (other factors were taken into consideration for selection). No attempt at all was made to establish controls or standards of any kind in these groups with a view to making later comparisons.

Although the approach to the three groups was different, the therapy for these groups re mained, where possible, the same. That is, going into feared situations, practising nonavoidance; symptom-analysis (i.e., analyzing tricks of an avoidance, postponement, starting, release nature, etc.), changing the pattern, using prolongations, cancellations, etc., besides the attention given to the personal problems (included here were those problems also arising because of specific speech assignments) of each stutterer.

The third group was the least dynamic of the three. Its members were prepared to accept the word of authority and laid all responsibility on this authority figure, hence cooperating little and avoiding tasks and assignments which required will and perseverence. The first two groups were. more dynamic. The material presented was more versatile and mature in concept. More work was accomplished and to a great extent each member was aware of his own responsibility towards therapy. Of the two, however, the second group (i.e., handled with the Socratic approach) was by far the more fruitful, the more strenuous in terms of involvement, and the most interesting to observe. Perhaps this was so because of the very nature of a more "non-directive" method. The members of the group were more personally threatened thom would be otherwise. They were made to "discover" for themselves. With very little help from the clinician they made clear many pertinent facts about stuttering and discussed most of the basic problems that we are confronted with in the stuttering problem. They appeared to have an excellent understanding of the problem and related points raised in regard to themselves. The following are some comments made by some of the group members :

In discussing various ways of measuring the severity of stuttering one patient offered the following-"Measure the frequency of the stuttering and the distortion to communication -i.e., the ability to make sense."

In discussing rationalization, one patient admitted, "I feel that stuttering is a kind of rationalization behaviour and I would feel bad if it were removed-it might account in our minds for our more basic inadequacies. Perhaps we feel inadequate anyhow and that stuttered speech is not the only problem."

In a general discussion of the definition of stuttering one patient said: "I feel it's a mental

\section{PETER ROTHENBERG (PTY.) LTD.}

\section{ELECTRICAL and INDUSTRIAL INSTRUMENTS}

Manufacturers of :

Instruments under the Registered Trade Mark "PREI." Industrial and Electro Surgical
Instrument Repairs

98, Mooi Street, Johannesburg. P.O. Box 2471

Phones 23-0730 23-0888 
speech block-the block escapes from speech and the stutterer lets it bother him and tries to aroid it and that is the problem. As regards my own stuttering, the physical manifestations seem useless in that they don't achieve anything. But I still feel disturbed-I sleep badly and have a nervous stomach." Another patient remarked in reply to this: "I am interested in your stomach and bad sleeping-your physical weaknesses may result because of suppressing your feelings, so that the mechanisms you use are more socially acceptable ; its a penalty to pay!" The stutterer in question replied that "stuttering outwardly would be difficult and I would rebel against it. For me the indirect way might be better. I have to get out of it at all costs." (This particular patient could be termed an "Interiorized" stutterer as differentiated from the "Exteriorized" stutterer as described by Douglass and Quarrington in 1952 (11).

One patient said: "I see the great importance of fear and I can accept its concepts intellectually, but cannot do so on an emotional level. Overcoming fear will overcome the problem altogether and I can see that it is not the problem of fluency that is so important -in fact attempts to maintain fluency by "hook or by crook" might worsen the condition by increasing the anxiety."

Another said: "I find that I cannot avoid using my old devices as they are too much intact, but I see that I ought to stutter when I don't feel like it, so that I can consciously bring these old devices out and replace them by new better habits. But at the moment I have not got the courage to go out and have spasms on purpose."

These statements also serve to indicate the need for the group to think and discuss on the lines of personal problems and adjustments. They were neither encouraged nor discouraged to approach the problem in this way rather than in any other way.

During the latter part of the group sessions questions were asked the members in such $a$ way as to give an indication to the clinician, as well as to the members themselves, of their understanding of the problem. The type of questions asked also indicate the nature of the therapy. Some of the many questions asked were :

What do we mean by the objective attitude?

If you were a secondary stutterer but became completely and absolutely objec.. tive about your stuttering, do you think you would still continue to stutter?

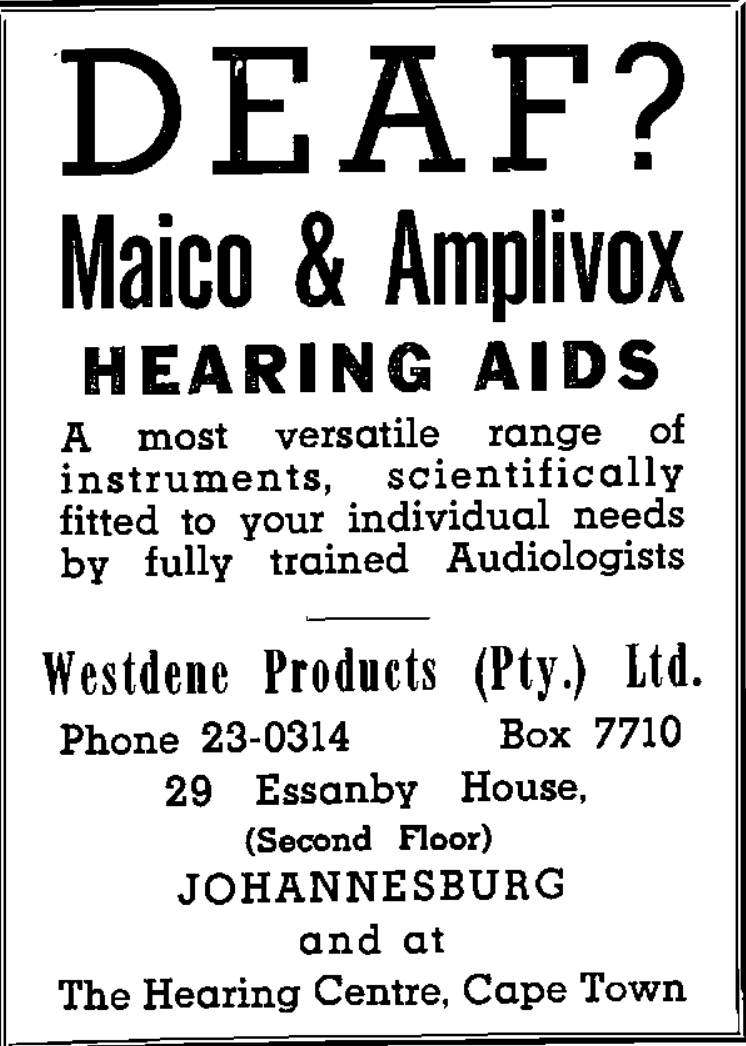

What is a starting device and when does it occur?

Must you know the rationale behind each step in treatment? Why?

Why is it that immediate pain and penalty and suffering seem to be necessary in successiul stuttering therapy?

Why must you fail during therapy?

Would you rather stutter and not have fear or would you rather have fears but not stutter?

Assuming a person is not just lazy. what other reasons could there possibly be behind his apparent lack of motivation in doing the work that is necessary in treatment?

Many answers to these questions were quite disorientated, and confused, while others, even on the same answer sheet, appeared to be quite reasonable. This in itselt is an interesting point and one which I would be tempted to connect with the problem of resistance mentioned later in this article.

Considering the total results of these three groups, I would say that when everything is boiled down, the same problems remain and these are likely to come up with whatever approach is used ,but incorporating 
the same therapy mentioned above). Stuttering can be considered as a defect of and hindrance to human relationships and as such must be dealt with as regards this relationship. Whether the educational period should be included or not. I feel, is a matter for debate.

The problems that occur and present themselves to the clinician most frequently are those problems concerned with changes that will occur within an individual in groups suci as these. We ask the stutterer to go into feared situations, to attempt to face up and not to avoid speech situations, to change his pattern of stuttering, to solve old attitudes and find new and better attitudes and hence we must expect changes with progress. As the demands of therapy increase so does the anxiety. This seems quite unavoidable if there is going to be any growth at all. The anxiety manifests itself in many ways but the most common, I find, is in the form of resistance. This resistance refers to breaking down of old habitual behaviour.

It is difficult to surrender old habits and attitudes. To the stutterer, as to anyone else, resistance is not new. He has been adept in it long before coming to the clinic and he witl use it in many deft ways to fool both clinician and himself. At times in a given situation. it almost appears that a patient might be stupid when it comes to clarifying a certain point and seeing the rationale behind it-something which had been repeated often enough to him and which he had previously appeared to understand. The most intelligent at times fail to comprehend a point when it has personal implications and even when they do comprehend, they cannot or will not relate it to themselves emotionally. Yet this must also be seen in its correct perspective. It is a problem of therapy, but, I feel, it is a necessary problem and one to be regarded as constructive rather than interfering. Resistance gives the patient the power to pull in the reins in his own time and to make the situation more tolerable, and when he can go further without great harm he will do so. In this respect we must attempt to understand his dilemma. Sheehan (4) has said that "when a stutterer has rejected the opportunity of dealing with word and situation fears, he provides a focal point for the analysis and understanding of his own resistances." The breakdown and realization of these resistances by the patient, I feel, becomes an important issue in therapy and is a vital barrier to cross to readjustment in the individual and as regards his speech. Besides resistance to anxiety-provoking situations this problem could also possibly be seen in the light of resistance to change itself.

A further problem in therapy coupled with resistance is the stutterer's self-perception. it is surprising what little stutterers really know about how they stutter and what they look like when they do, although they might be aware of the moment of difficulty. I have seen some describe fairly keenly the stuttering pattern of another in the group, but when it comes to themselves, they steer sharply away from it, deny that they exhibit the particular behaviour that they do and are often confident that they are in fact disguising their stuttering to a large extent to the outside world. In this respect it can be seen that they will go a long way in attempting to avoid symptom-analysis and bringing up to consciousness the exact nature of their stuttering behaviour.

Successful stuttering therapy results in obvious emotional and intellectual changes, growth in maturity and sensitiveness, a new objective awareness in the stutterer of his own sensations, reactions, and feelings, as well as an increased awareness of the same factors in the people with whom he comes into contact. In short he has gained "insight" and perhaps this rather abstract ability is the crux to the whole matter of success. Working for the objective attitude can be considered as being analogus to that of gaining insight. Insight comes from experiencing and under-

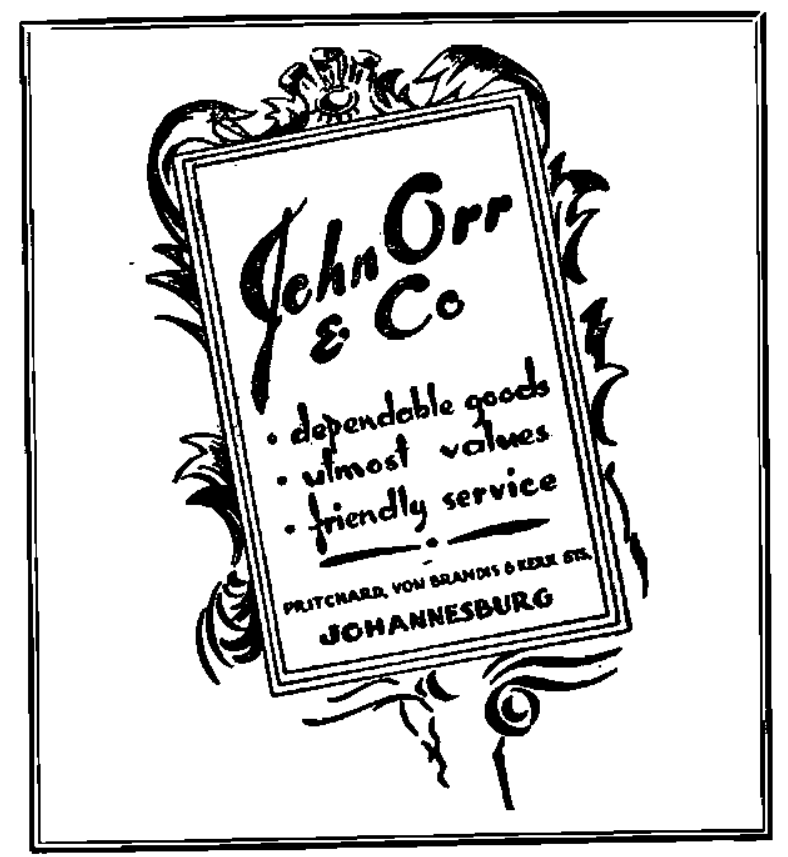


standing disruption, for without this unpleasant aspect, it woud not be significant. However, insight itself presents further problems to the clinicion. What degree of insight should a patient have? How far should we go and how much can we, as clinicions, give? I think it would be reasonable to expect that in some patients a great deal of insight would be harmful and undesirable, particularly when the patient is not mature enough, or not emotionally prepared to face up to deeper problems. We should expect a patient to attain that amount of insight which is sufficient "for his use in the problem at hand. Considera. tion must be given also as to the difference between "intellectual" insight and "emotional" insight, intellectual insight being where the patient understands and can "see" the issue, but which does not effect a fundamental change emotionally.

We see, therefore, that speech therapy can be related to psychotherapy in many ways when the above points, amongst many others, are taken into consideration, and I feel that therapists are very hesitant and reluctant to make this fact explicit. Without attempting to use psychotherapy consciously, speecn therapy, particulorly when used with stutterers, nevertheless involves psychotherapy, and this fact, if studied carefully, cannot be denied. The dynamics of speech therapy in fact imply and make obvious a therapy based on human relationships. Furthermore, theories of stuttering, preventative methods against stuttering developing, and many actual therapies, all amply indicate the significant part played by psychology and psychotherapy $(3$, $5,6,7,11)$.

The issue that is suggested here revolves around the use and the implications of psychotherapy in the work of the speech therapist at the present time. I feel that it is not out

\section{MISS BESSIE IDEMBO 54 WINGATE MANSIONS,}

\author{
c/r. Smit and Nugget Streets, \\ Hospital Hill, \\ Johannesburg.
}

Phone 44-0860

Typing and roneoing undertaken, especially Theses and Students Notes. of place to suggest that, at this stage, we as speech therapists ask ourselves-"What exactly do we do in speech therapy?"- to make quite clear the dynamics, criteria and principles we employ, in order to appreciate the scope of our work.

\section{REFERENCES :}

1. Goldstein K-."Language and Language Disturbances." Grune and Stratton, New York, 1948.

2. Eisenson, J.- "The Psychology of Speech." Appleton-Century-Crofts, Inc, New York, 1938.

"3. Sheehan, J.- "An Integration of Psychotherapy and Speech Therapy through a conflict theory of stuttering." Journal of Speech Disorders, 19 December, 1954.

4. Sheehan, I.-"Theory and Treatment of Stutter. ing as an Approach-Avoidance Conflict." University of California, 1952.

5. Van Riper, C.--"Speech Correction: Principles and Methods." Prentic Hail, New York, 1954.

6. Johnson. W.-"People in Quandries." Harper, New York, 1946.

7. Bryngelson, H., Chapman and Hansen--"Know Yourself." Burgess, Minneapolis, 1950.

-8. Ingham, H. and Love, L.- "The Process of Psychotherapy." McGraw-Hill Book Company, Inc., 1954

9. Backus, O.-"The Use of Group Structure in Speech Therapy." Journal of Speech Disorders June, 1952.

10. Bauman, S.-"An Organismic Approach to the Therapy and Practice of Group Therapy as a Remedial Technique in Speech Therapy." M. A Thesis, University of the Witwatersrand, Johannesburg.

11. Douglass, E. and Quarrington, B.-"The Differentiation of Interiorized and Exteriorized Second. ary Stuttering." Journal of Speech Disorders, December, 1952.

P.O. Box 10482 Telephones 22-4656

23-9432

\section{ABE ETKIND (PTY.) LTD.}

WHOLESALE MERCHANTS

First Floor, LINCOLN HOUSE,

57 Pritchard Street,

Johannesburg.

WORLD'S FINEST HEARING-AIDS.

3 TRANSISTOR From $£ 29 / 15 / 0$ 